\title{
. \\ Potentially incapable patients objecting to treatment: doctors' powers and duties
}

Kerri Eagle LB(Hons), LLM, FRANZCP Forensic Psychiatrist

Christopher J Ryan MB BS, MHL, FRANZCP Senior Clinical Lecturer

1 Justice and Forensic Mental Health Network, Sydney, NSW.

2 Discipline of Psychiatry and Centre for Values, Ethics and the Law in Medicine University of Sydney, Sydney, NSW.

kea30788@

bigpond.net.au

doi: 10.5694/mjal2.11814

Previously in this serie

"Ethics series - 3 " in MJA 2013; 199: 288-292

Series Editor Dominic J C Wilkinso MBBS, DPhil, FRACP ccasions of potential involuntary detention of patients who refuse treatment are not limited to dramatic situations involving the police, with such unfortunate outcomes as John's. ${ }^{1}$ Consider the following scenarios: in a coronary care unit, a man wants to discharge himself without explanation one day after having a myocardial infarction; in a general practice waiting room, a patient with a serious head injury makes for the door saying he can't wait; in an emergency department, a young woman wakes up from a presumed overdose and demands to leave. In each of these scenarios, patients are refusing assessment or treatment, but there is reason to suspect that they may lack the capacity to refuse treatment or may suffer from a mental illness.

In this article, we present a clinically oriented guide to scenarios like these, grounded in a previously published detailed legal analysis. ${ }^{2}$ First, we describe a doctor's powers when a patient is known to lack decision-making capacity (DMC) or is known to be mentally ill. Next, we suggest that when a person's DMC or mental state is unknown, the law provides a limited justification to briefly detain a patient when there is a strong reason to suspect that he or she may lack DMC or be mentally ill, and when refusal of treatment may place the patient at risk of serious harm. Third, we review any duty of care that a doctor may have to act in these circumstances.

Legal powers when a patient is known to lack decision-making capacity or be mentally ill

The law places enormous emphasis on a competent adult's right to self-determination, and an adult patient with "no mental incapacity has an absolute right to choose whether to consent to medical treatment" or refuse it. ${ }^{3}$ Most medical assessment or treatment of adults with DMC will only be lawful if it is consented to. Detaining a patient against his or her will may constitute false imprisonment.

In the New South Wales case, Hunter and New England Area Health Service v A, Justice McDougall acknowledged that when patients refused treatment, there were sometimes two conflicting interests: the competent patient's right to autonomy; and the state's interest in preserving life. ${ }^{4}$ In attempting to resolve this conflict, McDougall $\mathrm{J}$ had regard for Lord Donaldson's comments from an earlier English case and said, all things being equal, "the individual patient's right was paramount" but that "if there were doubt as to the individual's expression of preference, 'that doubt falls to be resolved in favour of the preservation of life $\mathrm{e}^{\prime \prime}$.

Under the law, all adults are presumed to have the capacity to consent to, or refuse, medical treatment unless and until that presumption is rebutted. ${ }^{4} \mathrm{~A}$ person lacks DMC to make a particular decision if he or she "is unable to comprehend and retain the information which is material to the decision ... or is unable to use and weigh the informa-

\begin{abstract}
Summar
- Generally, a patient may only be assessed and treated with his or her consent.

- It is difficult to interpret the law regarding doctors' powers and duties to assess and treat in cases where a patient refuses to accept medical advice but it is unclear whether the patient has decision-making capacity (DMC) or whether they are mentally ill.

- An examination of legal principles in this area suggests that there is a limited justification for doctors to detain a person for the purpose of assessment if they have good reason to suspect the person may either lack DMC or be mentally ill and if failure to detain the person is likely to lead to serious harm.

- This limited justification to detain would only apply for as long as the uncertainty about DMC or mental illness prevailed.

- Doctors have a duty to provide appropriate advice to patients who want to leave their care in circumstances where medical assessment or treatment may be required. Whether there is also a duty to detain someone in this situation is less clear, but we provide guidance to health care practitioners faced with this situation.
\end{abstract}

tion as part of the process of making the decision". ${ }^{4}$ The fact that the decision may seem irrational is not, on its own, sufficient to overturn the presumption of capacity. ${ }^{3}$

Australian states and territories have guardianship legislation that provides some mechanism for substituted consent once it is clear that the person lacks DMC (Box). These statutes allow patients to be treated in an emergency, without substituted consent, where treatment is considered necessary to save the incompetent person's life or prevent serious damage to the patient's health. However, if it is not yet clear that the objecting patient lacks DMC - and incapacity is only suspected - these statutes do not apply.

Every jurisdiction in Australia also has mental health legislation that provides for the detention of people with mental illnesses to allow assessment and treatment (Box). Once patients are detained under these acts they may be given psychiatric treatment and, in some cases, medical treatment without the need for consent. Just as guardianship legislation provides no assistance in the management of a patient if incompetence has not been established, mental health legislation is unhelpful in the management of objecting patients if mental illness is suspected but there has been no opportunity for assessment.

\section{Justification for restraining a patient when incapacity or mental illness is suspected}

In some cases the courts have determined that it may be justified to restrain a person when it is unclear whether they lack DMC or suffer from a mental illness. In the 19th century English case, Scott $v$ Wakem, a man with delirium 
tremens who was consequently likely to have been incompetent, and who had threatened to kill his wife, brought an action against the "medical man" who restrained him. ${ }^{5}$ The judge commented that, if at the time of the original restraint the person was likely to do mischief to anyone, the doctor would have been justified in restraining him, "not merely at the moment of the original danger, but until there was reasonable grounds to believe that the danger was over". 5

In Watson $v$ Marshall, the Australian High Court considered a case where a former doctor brought an action for false imprisonment against the medical superintendent of a psychiatric hospital. ${ }^{6}$ The Court referred to Scott $v$ Wakem and other cases 7,8 and noted that, in those cases, the lawfulness of an act of restraint depended on the "overriding necessity for the protection of himself or others". 6

In these and several other cases, courts have recognised a justification for the "otherwise unlawful restraint" of a person who may be a danger to themselves and others for the purpose of an examination "by proper persons" or "until the regular and ordinary means can be resorted to". However, this would apply only in circumstances of "obvious necessity" and "could not be extended to ordinary cases".. .

We feel that these cases provide a basis at common law for lawfully restraining a patient in circumstances where there is suspected incapacity and where the restraint is necessary for the protection of the patient or others. Restraint could be applied only as long as the necessity prevailed or until other means of consent could be resorted to.

\section{Duty of care to provide advice, assess decision- making capacity and detain}

Doctors owe a duty of care to their patients to provide advice, care and treatment. The care provided should be of a standard that would be widely accepted by peer professional opinion as competent professional practice. Doctors are also under a duty to provide patients with information that any patient would feel was relevant to the decision at hand and any other information that the doctor should have known would have been important to that particular patient (Box). ${ }^{10}$ When a patient refuses to wait for a full assessment, there is a duty to at least provide appropriate advice. In the NSW case, Wang $v$ Central Sydney Area Health Service, the court found the health service negligent in failing to provide appropriate advice to a young man with a head injury who decided to leave an emergency department waiting room without waiting to be seen by a doctor. ${ }^{11}$

A number of cases suggest that there is also a legal duty to assess DMC where there is uncertainty about its presence and where there are potentially serious consequences if treatment is refused. Uncertainty may arise in circumstances where the nature of a particular injury (such as a head injury) or the person's presentation (such as a reduced level of consciousness) suggests that his or her capacity may be impaired.

Ms B $v$ An NHS Hospital Trust was an English case involving a 43-year-old woman with tetraplegia due to a cervical spine cavernoma, who sought withdrawal of artificial ventilation. ${ }^{12}$ The judge held that when there was doubt about the DMC of a patient, the doubt should be

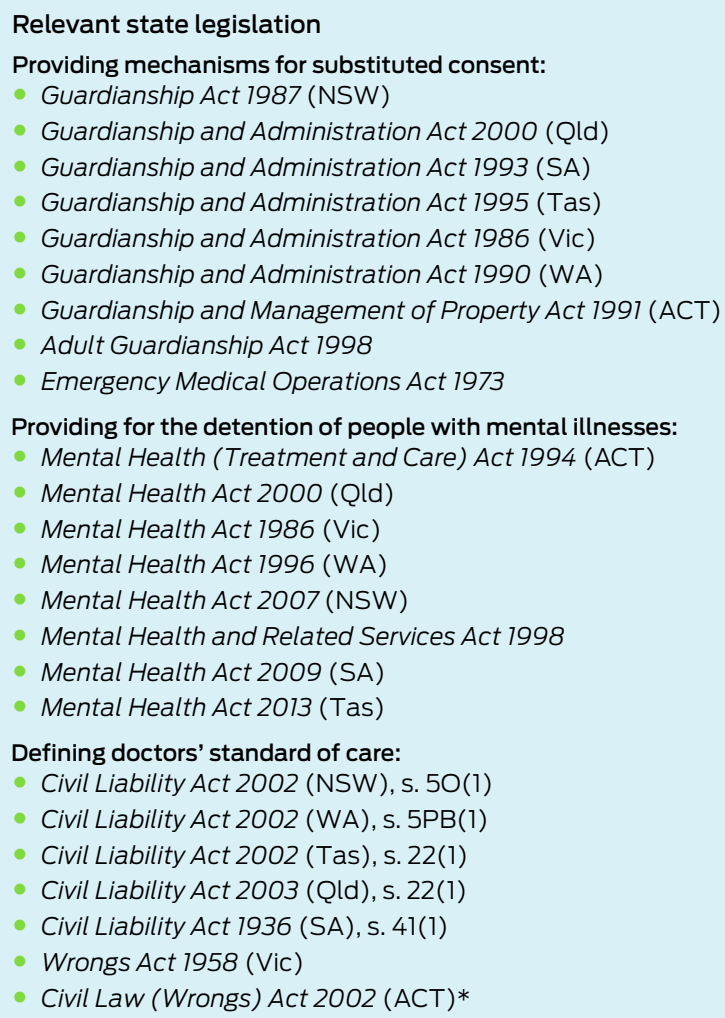

The standard of care in the Australian Capital Territory is different (see s. 42): "a reasonable person in the defendant's position who was in possession of all information that the defendant either had, or ought reasonably to have had, at the time of the incident".

"resolved as soon as possible", and that while the issue of capacity was being resolved, the patient should be cared for "in accordance with the judgment of the doctors as to the patient's best interests". ${ }^{12}$ Guidelines set out in another English case suggested that doctors should identify any problem with capacity as soon as possible and assess this as a priority. These guidelines also suggested that if there was "a real doubt as to capacity the issue should be referred for resolution by the Court". ${ }^{13}$

In contrast to decisions involving medical illness, the courts have so far declined to find that doctors have a duty to detain a person whom they suspect may have lost DMC or require treatment due to a psychiatric illness. ${ }^{14-16}$ Nonetheless, the law does not appear to be settled in this area, and it is possible that future cases may find a similar duty exists.

\section{Conclusion}

The courts place a high value on personal autonomy. However, autonomy is lost where DMC is lacking and, if this is not recognised, individuals may be deprived of necessary treatment. In cases where there is good reason to suspect that DMC is impaired and treatment refusal may involve significant risk, there is a duty to clarify the situation as soon as possible. Breach of that duty may give rise to a legal action for damages.

The law in this area is not clear, reflecting the reality that situations involving possible loss of DMC and a doctor's duty to act are often complicated and may require urgent 
action. The courts have acknowledged this and recommended that doctors act in the best interests of a patient until the ambiguity can be resolved. Using the reasoning we have laid out above, we suggest the following approach when faced with a patient who refuses assessment and attempts to leave the hospital.

If there are no factors to suggest the patient lacks DMC or suffers from a mental illness, or if there are such factors but there is no foreseeable risk of serious harm to self or others, then the person should be given appropriate advice, and his or her decision to leave should be respected.

If, on the other hand, there is:

- a known factor, such as a serious head injury, which may give rise to a lack of DMC; or recent behaviour such as an overdose which might suggest the presence of mental illness; or a decision to object to assessment or treatment that, in the context, is so unusual or inappropriate as to lead a reasonable person to suspect that the patient's DMC may be impaired; and

- a foreseeable risk of serious harm to that person or others; and

- no less-restrictive way of clarifying the person's capacity to refuse assessment or prevent the risk;

then, a clinician should detain a person for as long as necessary to minimise the risk and/or until "regular and ordinary means" can be resorted to.
There appears to be a limited legal justification to detain the patient, using the least amount of force possible and certainly no more force than is proportionate to the danger to be avoided. The regular and ordinary means would likely include an assessment, and in the event that the patient is found to lack DMC or suffer from a mental illness, provision of care under the appropriate legislative or common law provisions. In cases where there is genuine doubt that is unable to be resolved, clinicians should consider detaining the patient and seeking direction from the court or an appropriate tribunal.

Competing interests: No relevant disclosures.

Provenance: Not commissioned; externally peer reviewed.

1 Roberts PA. The help that John does not want. Med J Aust 2014; 200: 347.

2 Eagle K, Ryan C. Mind the gap: the potentially incapable patient who objects to assessment. $A L J$ 2012; 86: 685-696.

3 Re T (Adult: Refusal of Treatment) [1992] EWCA Civ 18.

4 Hunter and New England Area Health Service v A [2009] NSWSC 761.

5 Scott v Wakem (1862) 176 ER 147.

6 Watson v Marshall \& Cade [1971] HCA 33.

7 Anderdon v Burrows (1830) 172 ER 674.

8 In re Hawke (1923) 40 WN (NSW) 58.

9 Antunovic v Dawson \& Anor [2010] VSC 377.

10 Rogers v Whitaker [1992] HCA 58.

11 Wang v Central Sydney Area Health Service [2000] NSWSC 515.

12 Ms B v An NHS Hospital Trust [2002] EWHC 429 (Fam).

13 St George's Healthcare NHS Trust v S [1998] 3 All ER 673.

14 Hunter Area Health Service \& Anor v Presland [2005] NSWCA 33.

15 Stuart v Kirkland-Veenstra [2009] HCA 15.

16 The Australian Capital Territory v Crowley, The Commonwealth of Australia and Pitkethly [2012] ACTCA 52. 